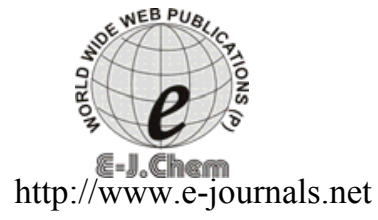

\title{
Chemical Modification on Reactive Dye Adsorption Capacity of Castor Seeds
}

\author{
V. DHARMALINGAM ${ }^{\S *}$, A. K. RAMASAMY ${ }^{\S}$ and V. BALASURAMANIAN \\ ${ }^{\S}$ Department of Chemistry, Periyar University, Salem, Tamilnadu, India \\ Department of Chemistry \& Environmental Science, AMET University \\ Kanathur, Chennai, Tamilnadu, India \\ dharma.che@gmail.com
}

Received 6 April 2011; Accepted 2 July 2011

\begin{abstract}
The roles played by four major functional groups (amine, carboxyl, azo, hydroxyl groups) in the biomass of castor seeds in adsorption of seven dyes were investigated. These functional groups in castor seeds were chemically modified individually to determine their contribution to the adsorption of ionic dyes. The dyes used were remazol red B, procino yellow, fast green FCF, brilliant cresyl blue, methylene blue, neutral red, red-141. It was found that hydroxyl group inhibited the adsorption of anionic dyes but it was major functional group in the adsorption of cationic dyes, hydroxyl group was important functional group in the adsorption of all seven dyes and the effect of methylation of amino group was not significant on the adsorption of seven dyes.
\end{abstract}

Keywords: Chemical modification, Dye adsorption, Castor seeds, IR spectrum, XRD

\section{Introduction}

Dyes are a kind of organic compounds which can bring bright and firm colour to other substances. Synthetic dyes usually have a complex aromatic molecular structure which possibly comes from coal tar based hydrocarbons such as benzene, naphthalene, antracene, toluene, xylene, etc. The complex aromatic molecular structures of dyes make them more stable and more difficult to biodegrade ${ }^{1,2}$. Today there are more than 10,000 dyes available commercially ${ }^{3}$. Synthetic dyes have been increasingly used in the textile, leather, paper, rubber, plastics, cosmetics, pharmaceuticals and food industries. The extensive use of dyes often poses pollution problems in the form of colored wastewater discharged into environmental water bodies. For some dyes, the dye concentration of less than $1 \mathrm{ppm}$ in receiving water bodies is highly visible, so that even small quantities of dyes can color large water bodies. This not only affects aesthetic merit but also inhibits sunlight penetration and reduces photosynthetic action. In addition, some dyes or their metabolites are either toxic or mutagenic and carcinogenic ${ }^{4,5}$. 
The conventional methods for removal of dyes from wastewaters include coagulation and flocculation ${ }^{6}$, oxidation or ozonation ${ }^{7,8}$, membrane separation ${ }^{9}$ and adsorption ${ }^{10}$. Activated carbon is popular and effective dye sorbent, but its relatively high price, high operating costs and problems with regeneration hamper its large scale application. Therefore, there is a growing need in finding low cost, renewable, locally available materials as sorbent for the removal of dye colors.

Some low cost botanic materials had directly been used as sorbent for dye adsorption from wastewater, which included apple pomace, wheat straw ${ }^{11}$ and orange pee ${ }^{12-18}$. But few researches had been done about the interaction between functional groups in biomaterial and a variety of dyes. In this paper, the roles played by four major functional groups (amine, imines, azo, hydroxyl groups) in the biomass of castor seeds in adsorption of seven dyes were investigated. The aim of this study was to identify the possible dye adsorption mechanisms of castor seeds. The dyes selected as sorbate were three cationic dyes.

\section{Experimental}

The dyes used in this study are listed in Table 1. Their chemical structures are shown in Figure 1. Seven dyes (remazol red B, procino yellow, fast green FCF, brilliant cresyl blue, methylene blue, neutral red, red-141), in commercial purity, were used without further purification. The dye stock solutions were prepared by dissolving accurately weighted dyes in distilled water to the concentration of $350 \mathrm{mg} / \mathrm{L}$. The experimental solutions were obtained by diluting the dye stock solutions in accurate proportions to needed initial concentrations. The initial $\mathrm{pH}$ of each dye solution was adjusted with $0.1 \mathrm{M} \mathrm{HNO}_{3}$ or $\mathrm{NaOH}$ using $\mathrm{pH}$ meter to its effective adsorption $\mathrm{pH}$ value obtained from the result of earlier experiments.

Table 1. The general data of seven dyes used in this study

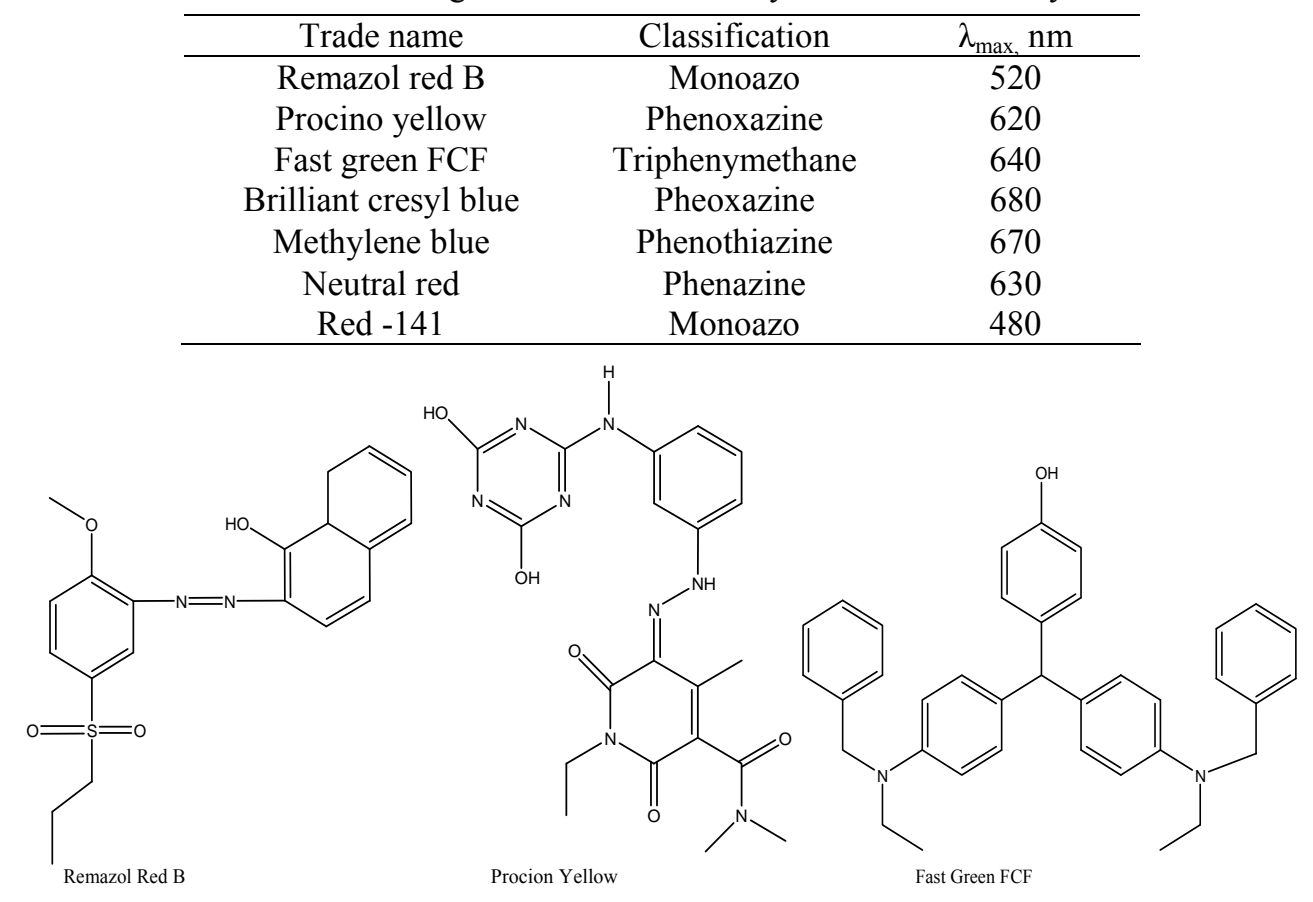


<smiles>Cc1c(N)cc(N)c2c1OC1=CC(=N)CCC1=N2</smiles>

Brilliant Cresyl Blue<smiles>N=c1ccc2nc3ccc(N)cc3[se]c-2c1</smiles>

Methylene Blue<smiles>Cc1cc2nc3ccc(N)cc3nc2cc1N</smiles>

Neutral Red<smiles>Oc1c(/N=N/c2ccc3ccccc3c2)ccc2cccc(Nc3ncncn3)c12</smiles>

Red -141

Figure 1. Chemical structures of the seven dyes used in this study

\section{Preparation of castor seeds sorbent}

The castor seeds used in this study was obtained from a local market. The collected biomaterial was extensively washed with tap water to remove dust then dried in an oven at $120{ }^{\circ} \mathrm{C}$ to a constant weight. Dry biomass was crushed into powder and sieved to different particle sizes, and then the biomaterial of uniform size [80 - 90 mesh] was preserved in the desiccators for further chemical modification.

\section{Chemical modification of the biomaterial}

\section{Methylation of amino group}

The modification of amino group was made according to the same method previously reported by shaking at ambient temperature $7 \mathrm{~g}$ (dry weight) of the raw biomass in $150 \mathrm{~mL}$ of formaldehyde ( $\mathrm{HCHO}$ ) and $360 \mathrm{~mL}$ of formic acid $(\mathrm{HCOOH})$ for $6 \mathrm{~h}$ at $125 \mathrm{rpm}$. Then the treated biomaterial was thoroughly washed with distilled water, filtered and dried. This treatment resulted in methylation of amino group. The general reactions scheme is:

$$
\mathrm{RNH}_{2}+2 \mathrm{HCHO}+2 \mathrm{HCOOH} \rightarrow \mathrm{RN}\left(\mathrm{CH}_{3}\right)_{2}+2 \mathrm{CO}_{2}+2 \mathrm{H}_{2} \mathrm{O}
$$

\section{Esterification of carboxyl group}

The carboxyl group of the biomass was methanol esterified following a similar method previously described ${ }^{19}$. Esterification was carried out by heating biomass of $9 \mathrm{~g}$ suspended in $633 \mathrm{~mL}$ of $99.9 \%$ pure methanol and $5.4 \mathrm{~mL}$ of concentrated hydrochloric acid (HCI) given a final acidic concentration of $0.1 \mathrm{M}$ HCI under efflux for $48 \mathrm{~h}$. Then the esterified biomaterial was thoroughly washed with distilled water, filtered and dried. The general reaction scheme of this treatment is:

$$
\mathrm{RCOOH}+\mathrm{CH}_{3} \mathrm{OH} \stackrel{\mathrm{H}^{+}}{\rightarrow} \mathrm{RCOOCH}_{3}+\mathrm{H}_{2} \mathrm{O}
$$




\section{Acetylation of amino and hydroxyl group}

According to the method previously used ${ }^{20}$, total acetylation of amino and hydroxyl group of the sorbent was carried out by refluxing the biomass suspension in acetic anhydride at $80{ }^{\circ} \mathrm{C}$ for $10 \mathrm{~h}$. Then the acetylated biomaterial was thoroughly washed with distilled water, filtered and dried. The general reaction scheme of this treatment is:

$$
\begin{gathered}
\mathrm{RHH}_{2}+\left(\mathrm{CH}_{3} \mathrm{CO}\right)_{2} \mathrm{O} \rightarrow \mathrm{RNHCOCH}_{3}+\mathrm{CH}_{3} \mathrm{COOH} \\
\mathrm{RCH}_{2} \mathrm{OH}+\left(\mathrm{CH}_{3} \mathrm{CO}\right)_{2} \mathrm{O} \rightarrow \mathrm{RCH}_{2} \mathrm{OCOCH}_{3}+\mathrm{CH}_{3} \mathrm{COOH}
\end{gathered}
$$

\section{Dye adsorption experiments}

The adsorption experiments of cationic dyes were carried out in a rotary shaker at $150 \mathrm{rpm}$ and at ambient temperature using $250 \mathrm{~mL}$ shaking flasks containing $100 \mathrm{~mL}$ dye solutions. The concentration and initial $\mathrm{pH}$ value of dye solution were $100 \mathrm{mg} / \mathrm{L}$ and 5.0, respectively. Four flasks were used for each dye. Raw, methylated, esterified and acetylated biomaterials (0.2) were respectively added to four flasks of each dye and then the flasks were sealed up to prevent change of volume of the solution during the experiments. After shaking the flasks for $24 \mathrm{~h}$, the samples were withdrawn from the flasks and dye solutions wee separated from the sorbent by filtration with a $200 \mathrm{mesh} / \mathrm{inch}$ stainless steel sieve then centrifugation. Dye concentrations in the supernatant solutions were determined.

The adsorption experiments of anionic dyes were carried out following a similar method as cationic dye adsorption, but the concentration and initial $\mathrm{pH}$ value of dye solution were $40 \mathrm{mg} / \mathrm{L}$ and 2.0 , respectively. Furthermore, 0.5 of raw, methylated, esterified and acetylated biomaterials were used and the adsorption time was $36 \mathrm{~h}$.

\section{Dye concentration determination}

Dye concentrations were estimated by measuring adsorbance at maximum wavelengths of dyes with a $752 \mathrm{~W}$ UV-Vis Grating Spectrophotometer and computing from the calibration curves. The amounts of dyes sorbed by the biomaterials were calculated using the following equation:

$$
\mathrm{q}=\left(\mathrm{C}_{0}-\mathrm{C}_{\mathrm{e}}\right) \mathrm{V} / \mathrm{W}
$$

Where $\mathrm{q}(\mathrm{mg} / \mathrm{g})$ is the amount of dye sorbed by biomass, $\mathrm{C}_{0}$ and $\mathrm{C}_{\mathrm{e}}(\mathrm{mg} / \mathrm{L})$ are the initial and equilibrium liquid phase concentration of dye, respectively, $\mathrm{V}(\mathrm{l})$ is the initial volume of dye solution, and $\mathrm{W}(\mathrm{g})$ is the weight of the biomass.

The experiments were conducted in duplicate and the negative (with no sorbent) and were simultaneously carried out to ensure that adsorption was by castor seeds biomass and not by the container.

\section{IR spectra and XRD study}

The IR spectra of raw and chemically modified sorbents were obtained using a Fourier transform infrared spectrometer (BIO-RAD FTS-40). For IR spectra. $5 \mathrm{mg}$ of biomass was encapsulated in $400 \mathrm{mg}$ of $\mathrm{KBr}$. Translucent disk was made by pressing the ground mixed material with the aid of a bench press (955 $\mathrm{kg}$ got $10 \mathrm{~min})$.

Crystallinities of the raw and chemically modified sorbents were determined by x-ray diffraction using a diffractometer (X'TRA ARL) operated at $50 \mathrm{k} \mathrm{V}$ and $40 \mathrm{~mA}$. The scanning scope and scanning speed were $5-55^{\circ}$ and $10^{\circ} / \mathrm{min}$, respectively, using $\mathrm{Cu} \mathrm{K}_{\alpha}$ radiation. 


\section{Results and Discussion}

\section{Effect of dye adsorption by chemical modification}

The effects of chemical modification on the removal ratios of cationic dyes. None of chemical modification increased dye adsorption ratios. After amino group methylation, removal capacities of three dyes decreased, but only a little. Esterification of carboxyl group induced rapid decrease of three dye adsorptions; this experimental result proved that carboxyl group was major functional group in the adsorption of cationic dyes. Total acetylation of amino and hydroxyl groups also decreased the adsorption percentages of all three dyes, but decrease extent was less than that of esterification, it indicated that hydroxyl group also was important functional group in the adsorption of cationic dyes.

Methylation of amino group increased slightly the adsorption ratios of three dyes. After carboxyl group esterification, three dyes were not completely removed from solution, it indicated that the carboxyl group bearing negative charge inhibited the adsorption of anionic dyes and in case removing the negative charge of carboxyl group by esterification, dye uptake capacities were obviously increased. Total acetylation of amino and hydroxyl groups extremely decreased the adsorption ratios of all three dyes, it showed that hydroxyl group was important functional group in the adsorption of anionic dyes.

\section{Influence of IR spectra and XRD by chemical modification}

The IR spectra of raw and chemically modified biomaterials are shown in Figures 2-5. From Figure 3, it could been seen, the broad mixed stretching vibration adsorption band of amino and hydroxyl groups at $3442 \mathrm{~cm}^{-1}$ was reduced, it was the result of methylation. Figure 4 showed that esterification brought reduction of stretching vibration adsorption band of carboxyl group at $1636 \mathrm{~cm}^{-1}$. Figure 5 indicated that the stretching vibration adsorption band of carboxyl group at $1637 \mathrm{~cm}^{-1}$ was obviously increased due to acetylation of amino and hydroxyl groups, and besides, an increase of the adsorption band at $1206 \mathrm{~cm}^{-1}$ also could been found.

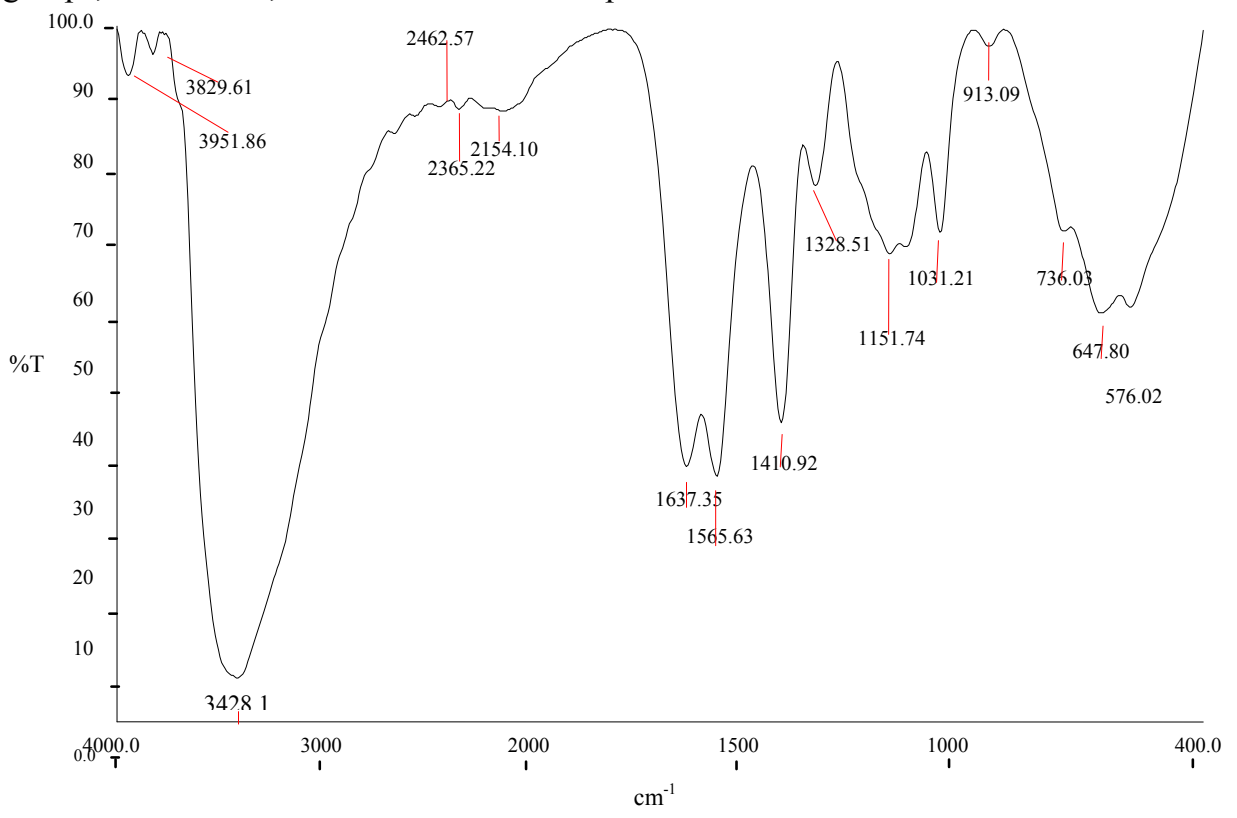

Figure 2. The IR spectrum of raw sorbent 
S340 V.DHARMALINGAM et al.

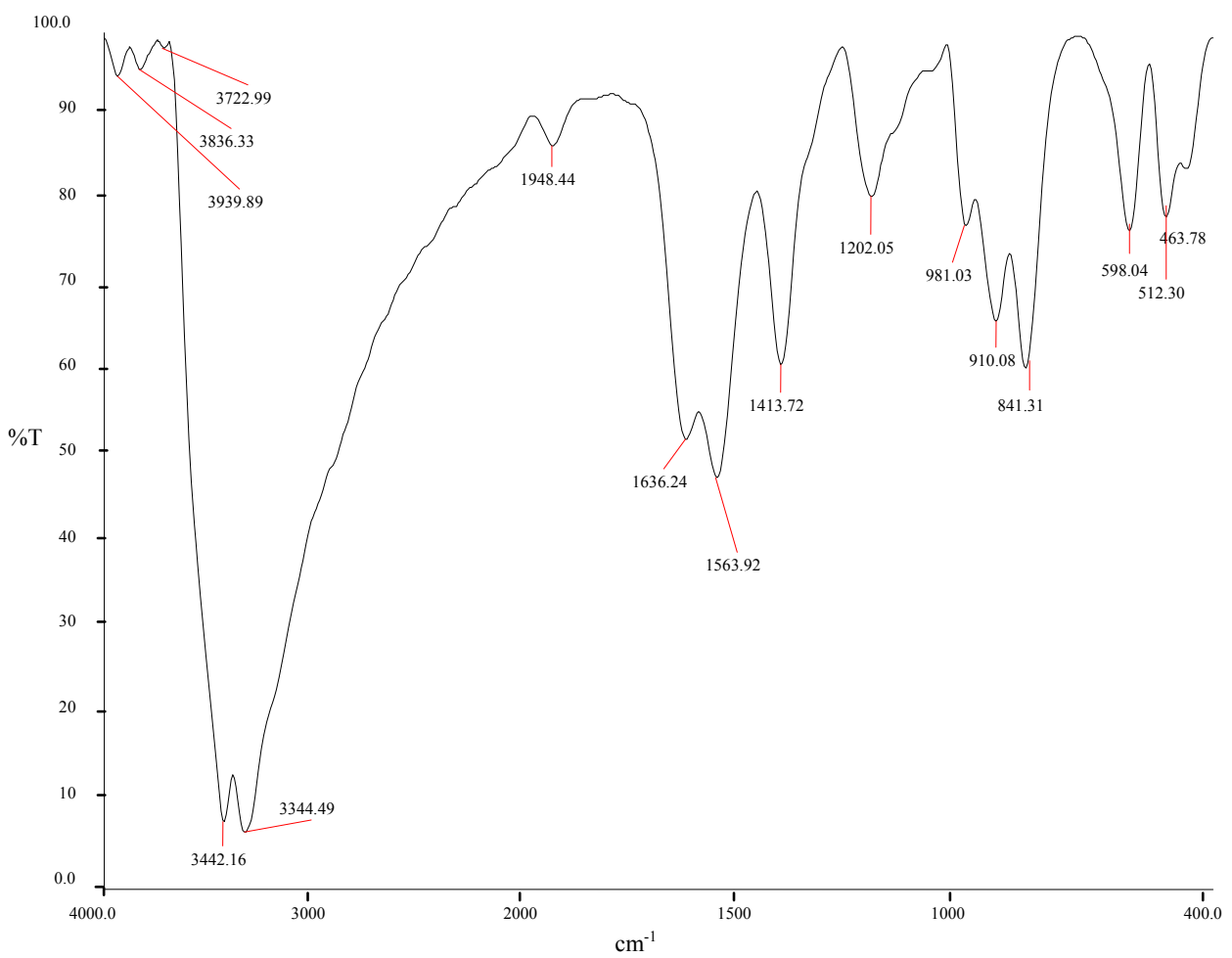

Figure 3. IR The spectrum of methylation sorbent

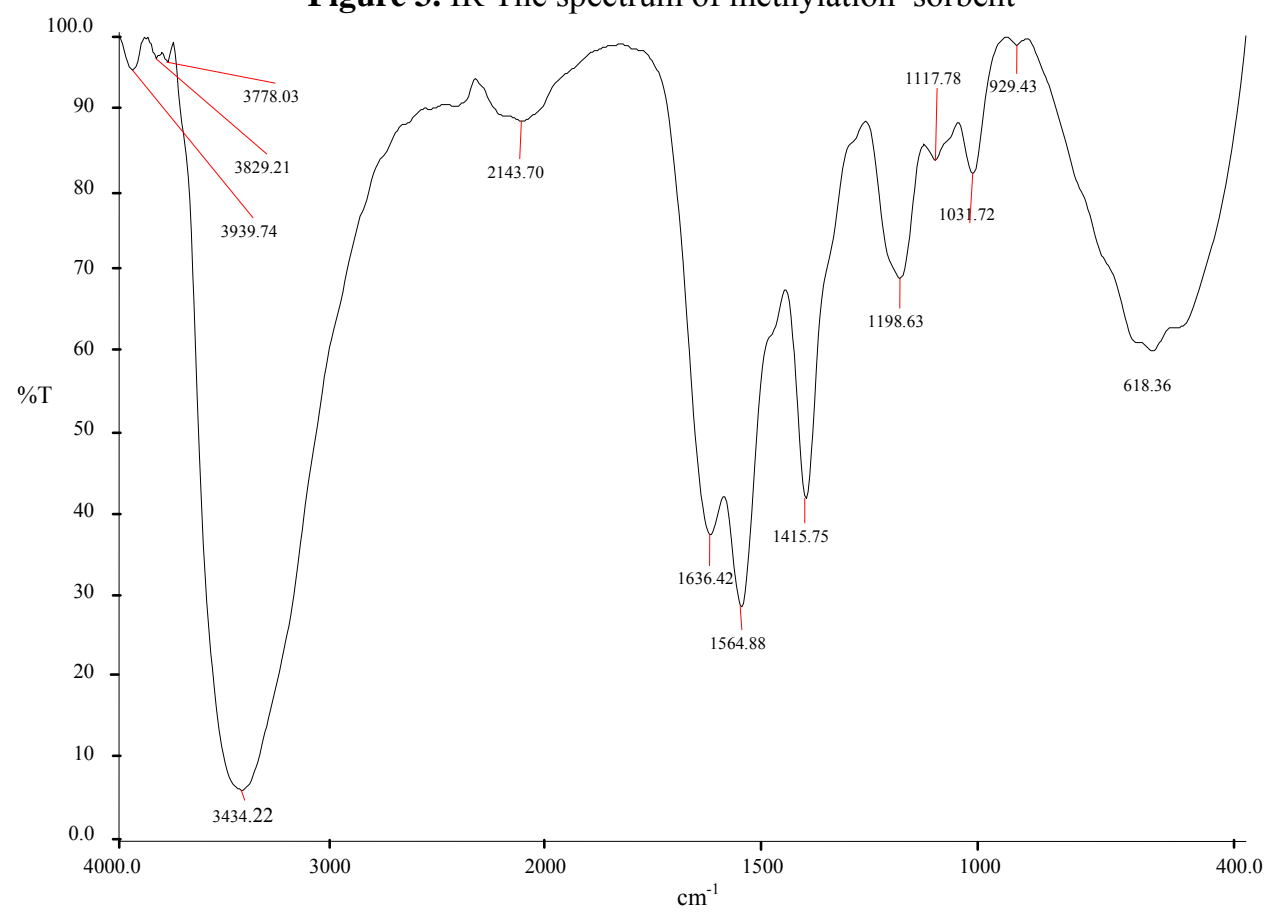

Figure 4. The IR spectrum of esterification sorbent 


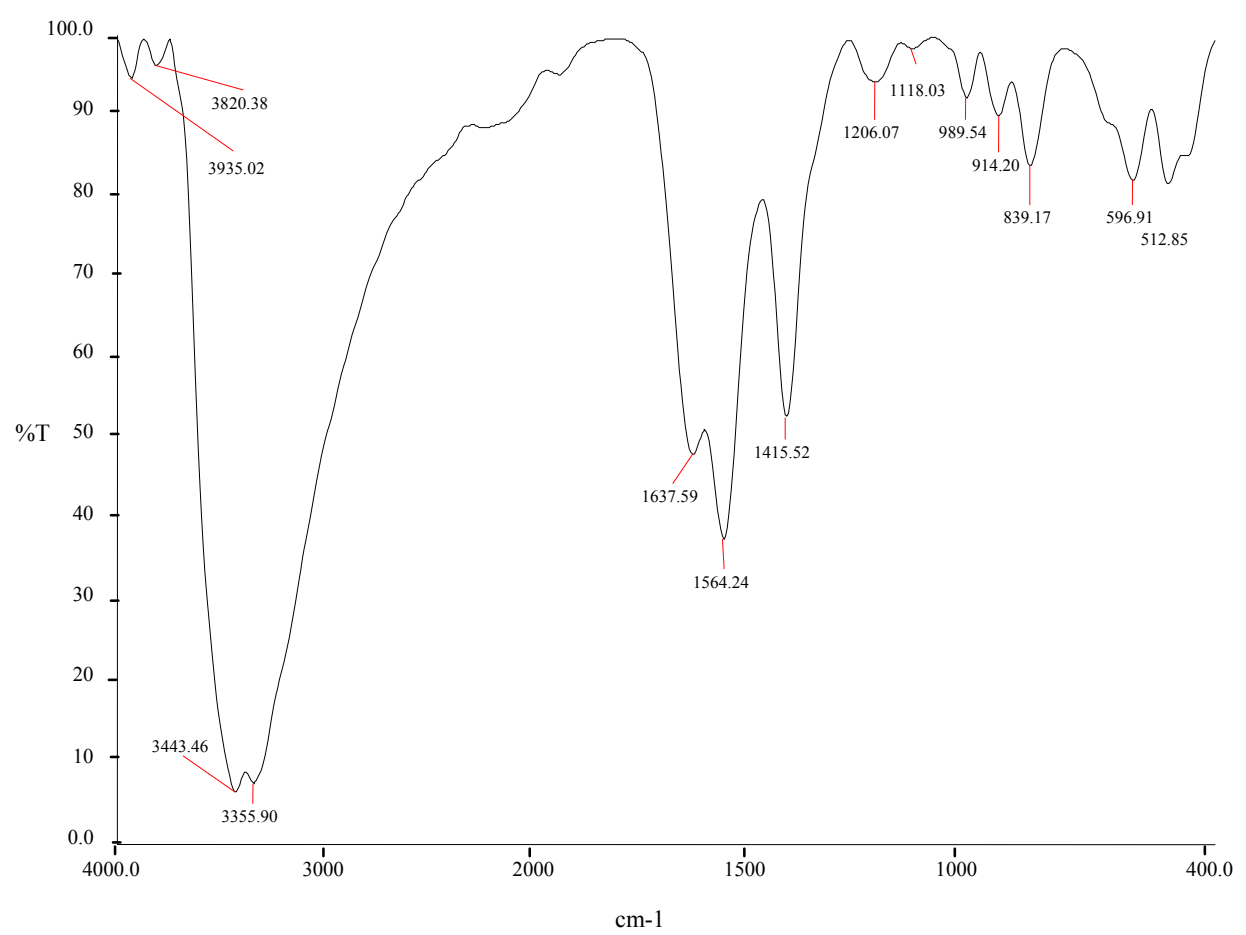

Figure 5. The IR spectrum of acetylation sorbent

The XRD diagrams of raw and chemically modified sorbents are shown in Figure 6. The XRD pattern of raw sorbent showed typical spectrum of cellulosic material, having main and secondary peaks at $2^{\theta}$ of $19^{\circ}, 33^{\circ}, 45^{\circ}$ and $55^{\circ}$ respectively ${ }^{21}$. The main peak is taken as indicative of the presence of highly organized crystalline cellulose, while the secondary peak is a measure of a less organized polysaccharide structure. The XRD diagram of methylation sorbent was very similar to that of raw sorbent. After carboxyl group esterification, the main and secondary peak heights in XRD diagram was increased, it indicated that the crystallinity of esterified sorbent was actually increased. Total acetylation of amino and hydroxyl groups induced disappearance of the secondary peak in XRD diagram.

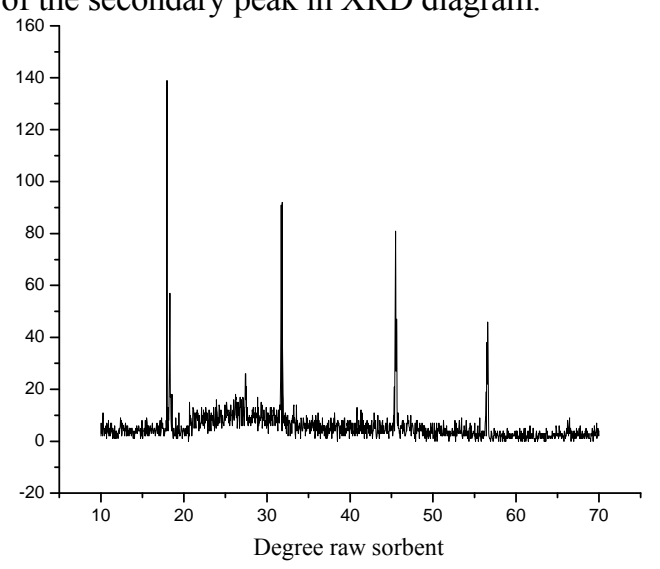



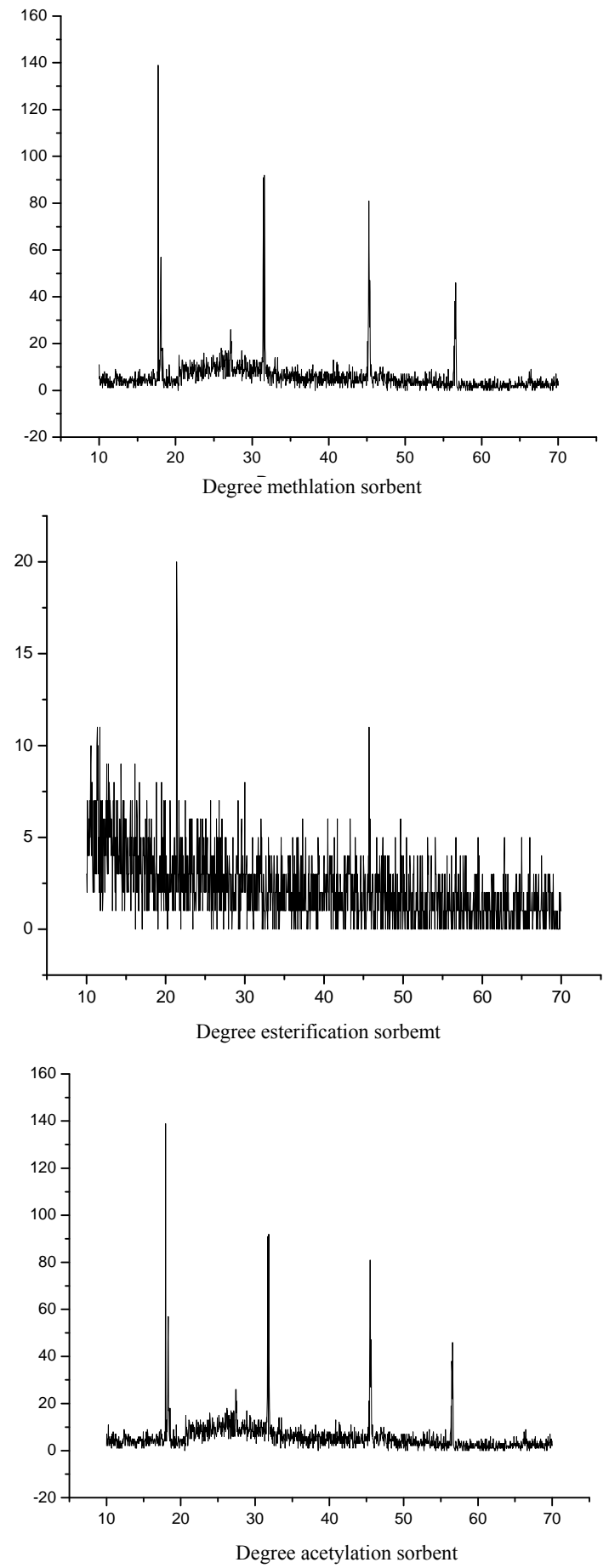

Figure 6. XRD diagrams of raw and chemically modified sorbent 


\section{Conclusion}

Studies on effects of chemical modification on dye adsorption on sorbent derived from castor seeds suggested the following conclusions:

- The effect of methylation of amino group on ionic dye adsorption was not significant. The possible reason was that at ambient temperature, the methylation could not be carried out completely due to the tough cell wall of castor seeds.

- The carboxyl group inhibited the adsorption of anionic dyes because of its negative charge and in case removing the negative charge of carboxyl group by esterification, anionic dye uptake capacity was obviously slightly increased. The carboxyl group was major functional group in the adsorption of cationic dyes.

- The hydroxyl group was important functional group in the adsorption of cationic and anionic dyes.

\section{Acknowledgment}

I thankful to Head of the Department of Chemistry, Periyar University and AMET University for providing laboratory facility.

\section{References}

1. $\quad$ Fewson C A. Trends Biotechnol., 1988, 6(7), 148-53.

2. Seshadri S, Bishop P L and Agha A M, Waste Manage., 1994, 15, 127-37.

3. Nigam P, Armour G, Banat I M, Singh D and Marchant R, Bioresour Technol., 2000, 72(2), 219-226.

4. Chen K C, Wu J Y, Huang C C, Liang Y M and Hwang S C J, J Biotechnol 2003, 101(3), 241-252.

5. Heiss G S, Gowan B and Dabbs E R, FEMS Microbiol Lett., 1992, 78, 221-6.

6. $\quad$ Panswed J and Wongchaisuwan S, Water Sci Technol., 1986, 18, 39-44.

7. Malik P K and Saha S K, Sep Purif Technol., 2003, 31, 241-50.

8. Koch M, Yediler A, Lienert D, Insel G and Kettrup A, Chemosphere, 2002, 46(1), 109-113.

9. Ciardelli G, Corsi L and Marucci M, Resour Conserv Recycl., 2000, 31, 189-197.

10. Venkata R B and Sastray C A, Indian J Environ Prot., 1987, 7, 363-376.

11. Robinson T, Chandran B and Nigam P, Water Res., 2002, 36(1), 2824-2830.

12. Namasivayam C, Muniasamy N, Gayatri K, Rani M and Ranganathan K, Bioresour Technol., 1996, 57, 37-43.

13. Annadurai G, Juang R S and Lee D, J Hazard Mater B, 2002, 92(3), 263-274.

14. Meyer V, Carlsson F H H and Oellermann R A, Wat Sci Technol., 1992, 26, 1205-1211.

15. McKay G, Ramprasad G and Mowli P, Wat Res., 1987, 21, 375-3777.

16. Robinson T, Chandran B and Nigam P, Bioresour Technol., 2002, 85(2), 119-124.

17. Gong RM, Ding Y, Li M, Yang C, Liu H J and Sun Y Z, Dyes Pigments., 2005, 64, 187-192.

18. Poots V J P, McKay G and Healy J J, Wat Res., 1976, 10, 1067-1070.

19. Tiemann K J, Gamez G, Dokken K and Parsons J G, Microchem J., 2002, 71, 287-293.

20. Bai R S and Abraham T E, Wat Res., 2002, 36(5), 1224-1236.

21. Atalla R H, The structure of cellulose: recent development. In: Soltes E J, Editor. Wood and Agricultural Residues, Research on use for Feed, Fuels and Chemicals, New York: Academic; 1983, 59-77. 


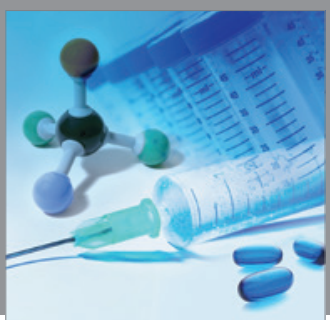

International Journal of

Medicinal Chemistry

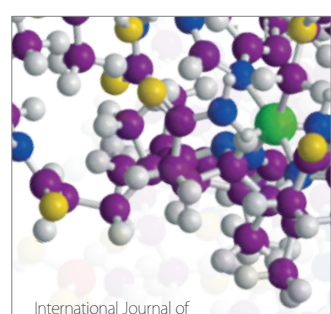

Carbohydrate Chemistry

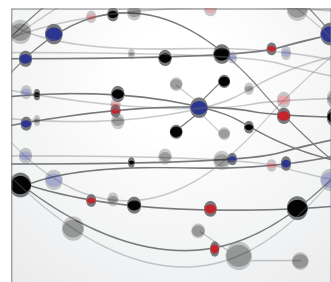

The Scientific World Journal
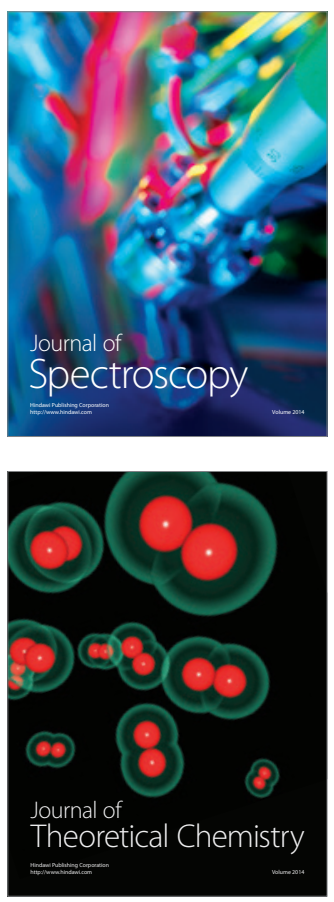
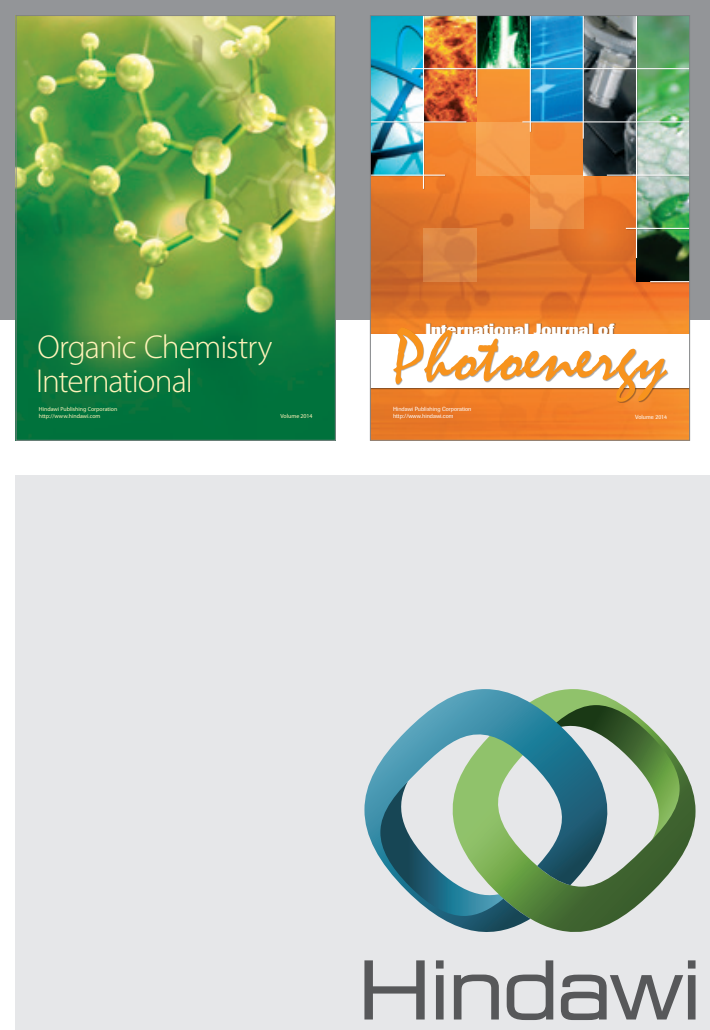

Submit your manuscripts at

http://www.hindawi.com
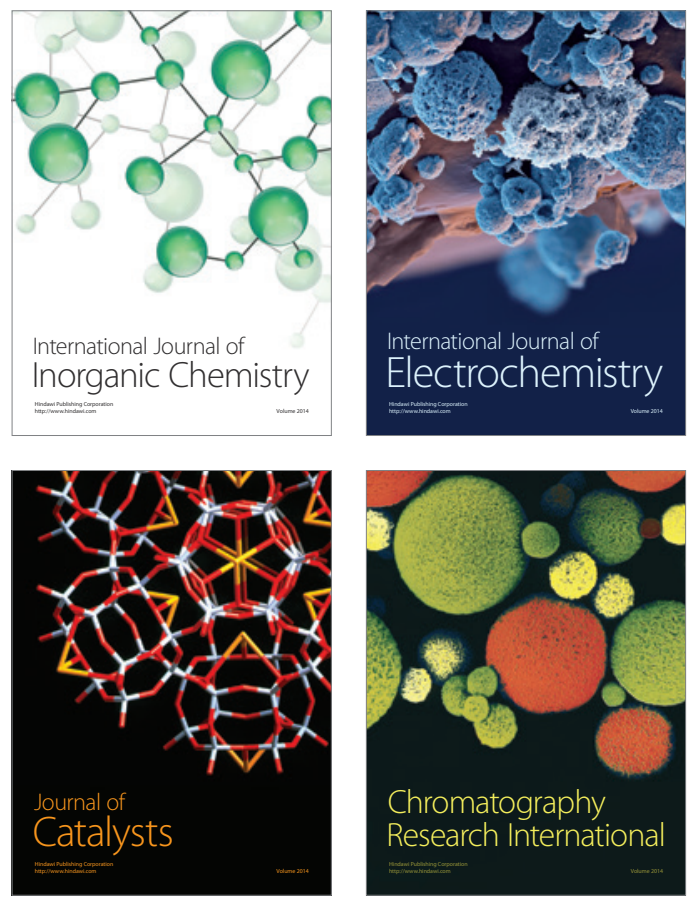
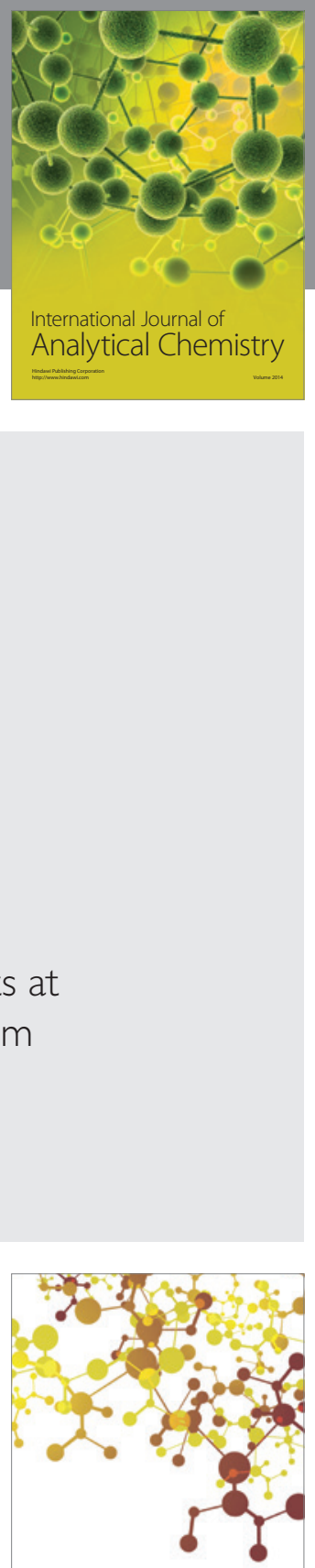

Journal of

Applied Chemistry
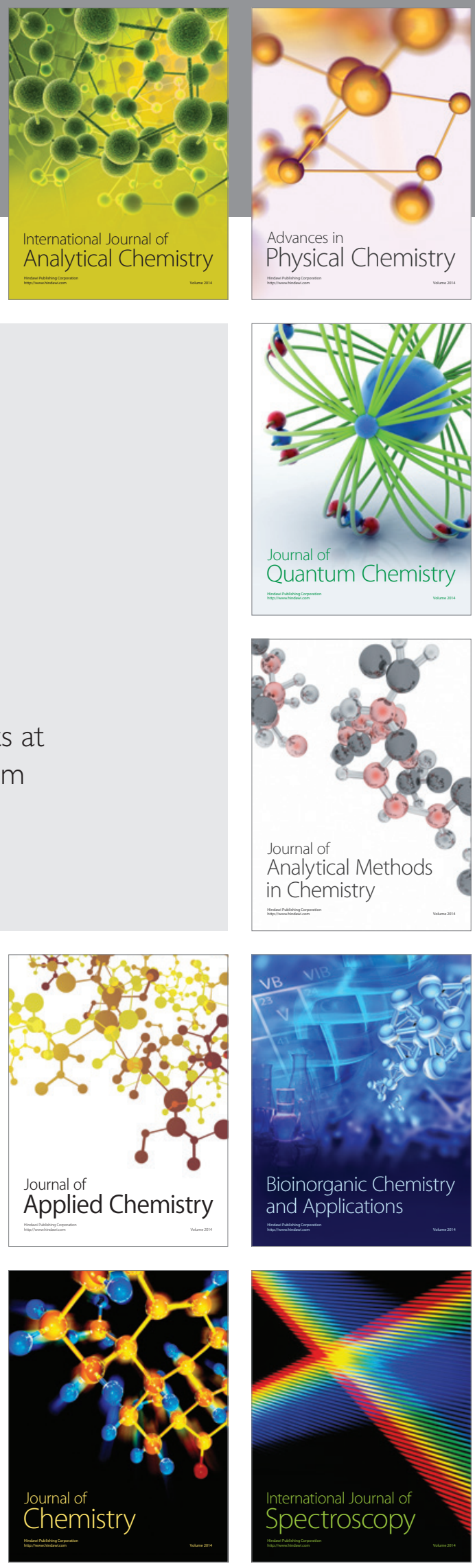